EPJ Web of Conferences 34, 01001 (2012)

DOI: $10.1051 /$ epjconf/20123401001

(C) Owned by the authors, published by EDP Sciences, 2012

\title{
Pierre in the lab's everyday life
}

\author{
Claudine Kahane $\mathrm{e}^{1, \mathrm{a}}$ \\ UJF-Grenoble 1 / CNRS-INSU, Institut de Planétologie et d'Astrophysique de Grenoble (IPAG) UMR \\ 5274, Grenoble, F-38041, France
}

\begin{abstract}
I shall evoke, through some memories of the pioneers years of the Grenoble Astrophysics Group, how Pierre played a decisive role in the lab's everyday life, as a computer wizard, as an insatiable inquiring mind and as an always careful and warm colleague.
\end{abstract}

\section{Introduction}

Other contributions describe Pierre's involvement in science management both at the local and at the national levels and his decisive role in the development of powerful computers networks for the scientific community. Pierre's research activity, so fruitful and various, will be present in all the scientific contributions of this tribute. I intend to evoke Pierre in the lab's everyday life. I want to show how his exceptional personality has been a founding element of the lab, almost since its creation and during thirty years. This contribution is complementary to that of Thierry Montmerle: I shall mainly evoke the lab's first years whereas Thierry Montmerle will focus on more recent events.

I entered the Grenoble astrophysics laboratory at a time when it was still a small research team named GAG (which means "joke" in French) for Groupe d'Astrophysique de Grenoble (as far as I remember, Pierre was one of the contributors to this name's choice). I shall evoke, through some dear memories, these pioneers' years, when Pierre played a decisive role not only as a computers' expert, to help the laboratory to get all the needed facilities, but also as a scientific itching powder, always ready to ask questions or to submit ideas to debate, and still more as a so friendly colleague, always of an infinite care to others, and so concerned with the collective interest.

\section{A computer wizard}

When the GAG was created in 1980 by Professor Alain Omont, in link with the birth of the frenchgerman-spanish Institute for Radio Astronomy in the Millimeter range (IRAM), our very tiny research group (two permanent researchers and two doctoral students, the first year and no more than ten members for several years) occupied only a few rooms in a building called CERMO, close to the present main laboratory building. The first years, our unique computer facility was a single terminal connected to the University Computer Center. Its use was both very inconvenient (the terminal was in fact a "teleprinter", with a keyboard and no screen) and very expensive (just to login and logout, the cost was the equivalent of 1 euro !). Pierre arrived at the laboratory in 1981, coming from the Bordeaux University, where he had spent five years, first as a $\mathrm{PhD}$ student (under the supervision of Ron McCarroll, see his contribution), then as a young and bright CNRS researcher. Of course, Pierre could not be satisfied with the lab's lack of computer and thanks to his endless energy and to his incredible ingenuity, he succeeded in a few months to buy, at rock-bottom price, the lab's first computer, a Digital PDP1134 machine, so tenderly loved by its first users! This precious computer was shelted in a cabin

a e-mail: Claudine.Kahane@obs.ujf-grenoble.fr

This is an Open Access article distributed under the terms of the Creative Commons Attribution License 2.0, which permits unrestricted use, distribution, and reproduction in any medium, provided the original work is properly cited. 
not much larger than a phone box, lent by the french-german institute ILL, with the complicity of Alain Castets. In a way, this small scale scientific collaboration was already announcing the large networks implying many labs and institutes that will start ten years later, thanks to Pierre's involvement in the development and sharing of intense calculation tools in Grenoble. To maintain this famous PDP1134 at the very top of all international standards and at the level of his always increasing need for powerful computers for quantum chemistry calculations, Pierre, as the genius theoretician do-it-yourself man he was, used to buy, in a computer junk yard near Paris, all kinds of second hand accessories (racks, memory cards, extensions and so on). They could not be easily sent and many of us remember having come back from Paris, with a car trunk full of dozens of such Pierre's indescribable bargains.

\section{An insatiable inquiring mind}

The heart of Pierre's scientific work was of course quantum mechanics and no one was more at ease with potential surfaces and wave functions than him. Under his impulse, a small group of theoretical chemistry was born at the GAG and went on developing in LAOG, with the recruitment of three permanent researchers, Claire Rist, Alexandre Faure and Laurent Wiesenfeld. However he was fond of discovering and exploring new research fields, in particular the interdisciplinary ones. The large variety of $\mathrm{PhD}$ thesis supervised by Pierre clearly shows how his broad mind was reluctant to limit his activity to narrow and specialized topics and how fertile he could be on a large number of subjects : after Claire Rist's thesis on quantum chemistry calculations of ammonia excitation, at the end of the '80s, he supervised Laurent Desbat's work on an applied mathematics subject dealing with deconvolution problems. A few years later, Alexandre Faure's thesis on a subject linked to astrochemistry, kinetics of neutral-neutral reactions in the cold interstellar medium, was followed by the supervision of Sebastien Sauge's work on an exotic physics topic, the Helium atomcules and by the $\mathrm{PhD}$ of Nicolas Maillard in the computer science field applied to quantum mechanics. Almost all of Pierre's students were present in Grenoble during Pierre's memorial day and have testified what an enthusiastic and challenging supervisor he was. The insatiable scientific curiosity of Pierre used to express everywhere and at anytime in the lab:

- first of course, during the seminars, to which he was a very regular and active attender; some "speakers of the day" certainly remember when they were confronted to his terrible "non specialist questions", always asked in a friendly and respectful manner, with a very sincere desire to make ideas and science progress

- most often, here or there, in front a cup of coffee or simply in a corridor; Pierre could captivate any of his chance interlocutors on any topic; discussing the last book he had read about the mystery of measurement in quantum mechanics or talking about the colloquium on Exobiology he was coming back from, he was always enthusiastic, excited and exciting.

Philippe Deterre tells in his contribution how his frequent discussions with Pierre about science, scientists, universe, religion and philosophy could fortunately end as a book. To tell the truth, the most difficult thing with Pierre was not to start a conversation, but to succeed to end it; I remember leaving the lab in a hurry to give a lecture, terrified by the though that I could meet Pierre on my way out and thus certainly arrive late.

\section{A careful and warm colleague}

Pierre was also, and probably above all, a wonderful every day's life colleague, always ready to hear and help others, even when he was very busy, always volunteer to imply himself in collective tasks and duties. One more memory, one of those happy tiny events with Pierre, that I like to think about: in the first years of GAG, Pierre and me were in charge of a very important general interest task, to choose the wall paint color for the room intended to become our library. Considering that bibliography was a fundamental research activity which deserves to take place in a pleasant and warm environment (at that time, computers had nothing to do with it!), we decided that apple green walls and fluorescent 
orange doors would nicely fit with the turquoise covers of A\&A and we were so efficient to convince the university technical service to paint our library that nobody had time to object before. No need to say that, a few years later, when the new LAOG building was under construction, no one asked us to choose the walls' color! In his relationship with each of us Pierre was extremely nice, friendly, paying attention to others, ready to answer questions and to help. I very rarely saw him angry. In contrast he was an essential factor of equilibrium and conviviality in the lab. Each time it was necessary, he knew how to defuse explosive situations by positive words. He was very patient and a very good teacher so that I still wonder why he never got involved in teaching activity. Maybe, he was afraid he could loose some of his beautiful non conformism...

Pierre had a very strong sens of honesty, uprightness and justice. Bright and respected researcher, he was also a man of convictions, much more involved in common interest tasks than in activities that would have benefit only his career. Just an example among many: with the tragic drowning of his son Vincent in the Drac accident in 1985, he personally experienced a drama caused by non respect of safety rules. A few years later, after the plateau de Bure cable car crash, he spent a lot of time and energy to help to drive a collective reflexion inside the CNRS, by his deep knowledge of the safety and responsibility questions. He was very aware of the CNRS important and specific role for french research and to the last limit of his strengths he was a very eloquent and convinced defender of this institution.

Pierre was a real life lover; he loved friends, feasts, foods and drinks. We all remember his enthusiastic participation to the labs' feasts, his remarkable hungriness in front of new culinary specialities, his powerful and contagious laugh.

\section{To Pierre}

In these times when, running after financial contracts, we risk to loose or to forget your beloved side paths of science, in these times when the words "public service" or "common interest", which were so important for you, are said to be out of use, in these times when conviviality, cooperative work, solidarity, which were the heart of your work, have become values in danger, we miss you so much, Pierre. 